\title{
Variation in Phenotype and Virulence Among Enzootic and Panzootic Amphibian Chytrid Lineages
}

\author{
C. G. Becker ${ }^{1 *}$, S. E. Greenspan², K. E. Tracy ${ }^{3}$, J. A. Dash ${ }^{3}$, \\ C. Lambertini ${ }^{4}$, T. S. Jenkinson ${ }^{5}$, D. S. Leite ${ }^{6}$, L. F. Toledo ${ }^{4}$, J. E. Longcore ${ }^{7}$, \\ T. Y. James ${ }^{5}$, K. R. Zamudio ${ }^{3}$,
}

${ }^{1}$ Departamento de Zoologia, Universidade Estadual Paulista, Rio Claro, SP 13506, Brazil

${ }^{2}$ College of Marine and Environmental Science, James Cook University, Townsville, Queensland, 4811, Australia

${ }^{3}$ Department of Ecology and Evolutionary Biology, Cornell University, Ithaca, NY 14853, USA

${ }^{4}$ Laboratório de História Natural de Anfíbios Brasileiros (LaHNAB), Departamento de Biologia

Animal, Universidade Estadual de Campinas, Campinas, SP 13083-862, Brazil

${ }^{5}$ Department of Ecology and Evolutionary Biology, University of Michigan, Ann Arbor, MI 48109, USA

${ }^{6}$ Departamento de Genética, Evolução e Bioagentes, Universidade Estadual de Campinas, Campinas, SP 13083-862, Brazil

${ }^{7}$ School of Biology and Ecology, University of Maine, Orono, ME 04469, USA

\section{${ }^{*}$ Corresponding author:}

C. Guilherme Becker

Departamento de Zoologia

Universidade Estadual Paulista - UNESP

Rio Claro, SP 13506-900, Brasil

Email: guibecker.br@gmail.com 


\section{Abstract}

The Global Panzootic Lineage of the fungus Batrachochytrium dendrobatidis ( $B d-\mathrm{GPL})$ is threatening amphibians worldwide. In contrast, four lineages $(B d$-Brazil, $B d-C H, B d$ Cape, and $B d$-Korea) that diverged early in the history of $B d$ have not yet been directly linked to amphibian declines. $B d$ likely evolves in response to strong selective pressure imposed by hosts and the environment, leading to differences among pathogen phenotypes and genotypes that may directly affect virulence. Here, we report on variation in phenotype, genotype, and virulence of $B d$-Brazil and $B d-G P L$. Specifically, we (i) used a controlled infection experiment to compare virulence between one $B d$ Brazil and three $B d$-GPL isolates on a North American amphibian host (Lithobates sylvaticus), (ii) tested for relative phenotypic and genotypic differentiation among $B d$ isolates from Brazil, and (iii) tested for possible correlations between environmental variables and $B d$ phenotypes. We found substantial variation in virulence among $B d$ GPL isolates and found that our $B d$-Brazil isolate showed virulence comparable to an average North American Bd-GPL. North American hosts infected with a $B d-G P L$ isolate from Panama did not show significant mortality. $B d$ phenotypes varied significantly across sampling locations; these phenotypes were neither spatially clustered nor correlated with any environmental variables. Additionally, we found a surprising lack of correlation between genotypic divergence and zoospore and zoosporangium sizes in our sample. Although $B d$-Brazil was less virulent, infecting $L$. sylvaticus than one $B d-$ GPL isolate, this endemic lineage still caused $\sim 50 \%$ mortality in our experimental North American hosts. This indicates that $B d$-Brazil has the potential to kill amphibians if introduced to naïve wild populations. Our findings underscore that characterizing virulence of multiple $B d$ isolates and lineages is important for understanding the evolutionary history and diversity of $B d$.

\section{Keywords}

Declines, anurans, chytridiomycosis, environmental pressure 


\section{Introduction}

Emerging infectious diseases have potentially destructive effects on wildlife, often causing severe population declines and extinctions (Daszak et al., 2000). Many pathogens are highly sensitive to variation in temperature, precipitation, and humidity (Colhoun 1973; Altizer et al., 2006), and thus their distributions and dynamics can be limited by macro- and micro-environmental conditions in their invasive ranges (Lomolino et al., 2009). Several recent wildlife epidemic outbreaks have been attributed to changes in environmental stressors that presumably trigger rapid pathogen proliferation and expansion (Epstein, 2001; Harvell et al., 2002; Pounds et al., 2006). Environment alone, however, does not explain variation in pathogen virulence and disease outbreaks. Genotypic differences among pathogen isolates can directly affect virulence (Fisher et al., 2009; Yap et al., 2014), and many pathogens show high adaptive potential, modifying both their phenotypes and genomes (Farrer et al., 2013) to increase transmission and fitness when encountering new hosts and environments (Reece et al., 2009; Searle et al., 2015). Thus, our ability to understand mechanisms underlying pathogen virulence depends upon characterizing both phenotypic and genetic diversity that is present in pathogen populations, and examining how those factors interact with hosts and the environment to produce different disease outcomes (Fisher et al., 2009; James et al., 2015).

The emergence of the fungal pathogen Batrachochytrium dendrobatidis $(B d)$ is a leading cause of global amphibian declines, especially in highly diverse tropical amphibian communities (Berger et al., 1998; Longcore et al., 1999; Cheng et al., 2001; Lips et al., 2008). Early comparative genetic studies of $B d$ isolates found low genetic diversity consistent with a rapid expansion of the pathogen (Morehouse et al., 2003; 
James et al., 2009). However, the recent discovery of highly divergent lineages from Brazil, South Africa, Switzerland, and Korea have vastly increased the known genetic diversity within this globally distributed pathogen (Farrer et al., 2011; Schloegel et al., 2012; Bataille et al., 2013). Genomic resequencing of global isolates revealed that a recently diversified and hypervirulent Global Panzootic Lineage (GPL) is associated with massive amphibian population declines in Central America, Australia, and North America (Farrer et al., 2011; Rosenblum et al., 2013). Four additional lineages, $B d-C H$, $B d$-Cape, $B d$-Korea, and the narrowly distributed $B d$-Brazil, are the earliest divergences in the evolutionary history of $B d$ populations (Bataille et al., 2013; Rosenblum et al., 2013; Jenkinson et al., 2016), and at least one of those lineages (Bd-Cape) showed lower virulence when compared to GPL (Farrer et al., 2011). Thus far, the phenotypic and genetic diversity and virulence of other non-GPL isolates have not been characterized.

Brazil harbors a large diversity of amphibian hosts (Toledo \& Batista 2012; Haddad et al., 2013) and is also home to two Bd lineages (Schloegel et al., 2012; Rodriguez et al., 2014; James et al., 2015). Bd-Brazil, a highly divergent lineage from Bd-GPL, was isolated from field localities in southeastern Brazil (Schloegel et al., 2012). In contrast, $B d$-GPL is widespread throughout the whole Atlantic Forest range (Rodriguez et al., 2014; Jenkinson et al., 2016). Extensive field collections have now demonstrated that $B d$-Brazil coexists (in some cases syntopically) with Bd-GPL in the southern part of the $B d-G P L$ range (Jenkinson et al., 2016), and retrospective analyses confirm that both lineages have been endemic in the Atlantic Forest for over $100 \mathrm{y}$ (Rodriguez et al., 2014). Furthermore, a hybrid isolate between Bd-Brazil and Bd-GPL 
was discovered within a narrow range of $10 \mathrm{~km}$ in southern Brazil (Jenkinson et al., 2016). Despite the high genetic diversity of $B d$ in Brazil's Atlantic forest, amphibian populations in Brazil do not show the massive population declines that are typical of areas of GPL emergence (Toledo et al., 2006; Becker \& Zamudio, 2011; Becker et al., 2014; Rodriguez et al., 2014; Becker et al., 2016a; Becker et al., 2016b). Although a few retrospective studies report the disappearance of stream-breeding frog species in some well-studied areas (Heyer et al., 1988; Weygoldt 1989; Eterovick et al., 2005), none of the published reports have to date directly attributed these population changes to $B d$ emergence. Therefore, host-pathogen dynamics of $B d$ in Brazil might fundamentally differ from those observed in the western US, Central America, and Australia. The long term presence of $B d$-Brazil in the Atlantic Forest, combined with the apparent absence of population declines in areas of high $B d$ prevalence has led to the suggestion that the endemic $B d$-Brazil predates the invasion of $B d$-GPL (Jenkinson et al. 2016), and that, perhaps, amphibian populations in Brazil are not significantly affected by $B d$ in the wild (Becker \& Zamudio 2011; Becker et al., 2016a). Lower Bd susceptibility in Brazilian amphibians could be due to the shared evolutionary history between $B d$-Brazil and local amphibian hosts that may have permitted the evolution of host defenses, especially if $B d$-Brazil is less virulent than $B d$-GPL. In this scenario, the evolution of host defenses developed against $B d$-Brazil may also have provided protection against $B d$-GPL at the time of its emergence. Additionally, $B d$-Brazil has been recently detected in the U.S. on an individual of Lithobates catesbeianus imported from a Brazilian bullfrog farm (Schloegel et al., 2012). The presence of Bd-Brazil in the U.S. underscores the importance of testing the virulence of this lineage in North-American amphibians. 
Here, we report on variation in phenotype and virulence among $B d$-GPL and $B d$ Brazil isolates. We used a controlled infection experiment to compare virulence among one $B d$-Brazil and three $B d$-GPL isolates on North American amphibians. We also genotyped and phenotypically profiled eight new isolates of $B d$ collected in Brazil, and tested for relative genotypic and phenotypic differentiation among them. Finally, we examined possible correlations between environmental variables and phenotypic differentiation among isolates. We found that $B d$ isolates, even those recently derived from a common ancestor, are phenotypically differentiated independent of environmental variables, which may have consequences for virulence and disease emergence.

\section{Materials and Methods}

\section{Larval Infections}

We estimated virulence of a $B d$-Brazil isolate (UM142) and three $B d$-GPL isolates (JEL258 and JEL404 isolated in Maine, U.S.A., and JEL423 isolated in Panama) using North American wood frogs (Lithobates sylvaticus) as the experimental host. We collected eight egg masses from a pond in Orono, Maine, U.S.A., and once tadpoles reached Gosner stage 26-30 (limb buds just beginning to emerge) we randomly assigned 10 tadpoles each to 20 tanks containing $8 \mathrm{~L}$ of water. Four tanks (40 tadpoles total) were then assigned to each of five treatments (four different $B d$ isolate treatments and one negative control). Experimental tanks were maintained at $22^{\circ} \mathrm{C}$ with a $12 \mathrm{hr}$ light/12 hr-dark cycle. $B d$ inoculations were performed on day 0 and on day 17 using $10^{6}$ zoospores per tank. Metamorphosis began on day 21, and metamorphs were 
moved to different containers in groups, with a small pool of water and wet paper towels. Survival was monitored daily, dead animals were noted, and dying animals were euthanized with an overdose of MS-222 if they showed lack of righting response, which is a typical sign of advanced stages of chytridiomycosis (Voyles et al., 2009). The experiment concluded on day 70 , at which point all remaining animals were euthanized.

$\mathrm{Bd}$ isolates, Phenotypes, and Genetic Characterization

Eight isolates of $B d$ were collected from May 2010 to February 2013 from infected tadpoles sampled at various Atlantic Forest localities (Table 1). Anuran larvae were screened in the field with a 10X hand lens for signs of chytridiomycosis by assessing the level of oral tissue dekeratinization (Knapp \& Morgan 2006). Animals with signs of $B d$ infection were euthanized, and oral tissues excised. Infected tissues were prepared for pathogen isolation on $1 \%$ tryptone agar with $0.2 \mathrm{mg} \cdot \mathrm{mL}^{-1}$ penicillin-G and $0.4 \mathrm{mg} \cdot \mathrm{mL}^{-}$ ${ }^{1}$ streptomycin sulfate. Isolates of $B d$ were maintained on $1 \%$ tryptone agar at $20-21{ }^{\circ} \mathrm{C}$ until sufficient growth had occurred for DNA extraction.

We measured phenotypes for the same eight $B d$ isolates (Table 1) following methods described in previous studies (Fisher et al., 2009; Flechas et al., 2013; Lambertini et al., 2016). Each $B d$ isolate was inoculated into $5 \mathrm{~mL}$ of liquid medium composed of $1 \%$ tryptone and incubated at $21 \stackrel{\circ}{\circ} \mathrm{C}$ for $7 \mathrm{~d}$. At the end of that period we aliquoted cultures of each $B d$ isolate in duplicate onto slides and took 30 photographs of random quadrats of each slide at 1000X magnification. We measured the diameter of the 60 largest zoospores and the 60 largest zoosporangia from each isolate using TSView® software (see Lambertini et al., 2016). 
To characterize genotypes, we harvested mature zoospores and sporangia from $7 \mathrm{~d}$-old cultures by scraping fungal tissue from agar plates. We extracted DNA using a standard CTAB miniprep protocol with chloroform and isoamyl alcohol (Zolan \& Pukkila 1986) and amplified each culture at 10 polymorphic loci. We used markers $8009 X 2$, BdC24, BdC5, BdSC4.3, BdSC4.16, BdSC6.15, BdSC8.10, BdSC3.1, BdSC7.6, and R6064 because they distinguish Bd-Brazil from Bd-GPL and are useful for studying Atlantic Forest populations (Jenkinson et al. 2016; Lambertini et al., 2016). Successful amplicons were purified using ExoSAP-IT (Affymetrix), and PCR products cyclesequenced with fluorescently labeled terminator nucleotides using the BigDye reaction kit (Applied Biosystems).

\section{Environmental Correlates of Bd Phenotypes}

For each source locality for our Bd isolates (Table 1) we recorded spatial information on latitude, and quantified elevation, mean annual temperature, and mean annual rainfall using Worldclim/Bioclim layers (1000m resolution), available at http://www.worldclim.org/bioclim (Hijmans et al., 2005). These metrics of temperature and precipitation are averaged from 50 y records (1950-2000) from a network of climatic stations throughout the globe.

\section{Statistical Analyses}

We quantified mortality for each of the five experimental groups of wood frogs (four groups, each infected as tadpoles with one of the four experimental $B d$ isolates and one uninfected control group). We used Analysis of Variance (ANOVA) to compare mean 
mortality at the end of the experiment in the five treatments, using tanks as replicates, and made pairwise comparisons between treatment means with the Fisher LSD test.

We used ANOVAs and the same post-hoc LSD tests for pairwise multiple comparisons to compare mean zoospore and zoosporangium size among the eight focal $B d$ isolates from Brazil. We computed genotypic distance among the eight isolates using the hetequal method (James et al. 2009), and then standardized distance values by the greatest distance measured (D/Dmax) (Fisher et al. 2009). D/Dmax values were compared to phenotypic distances [scaled zoospore size (DZSP/DZSPmax) and scaled zoosporangium size (DSPOR/DSPORmax)] with statistical significance assessed by Mantel testing with 1000 permutations (Fisher et al., 2009). Finally, we used simple linear regressions to test for associations between our four measured environmental variables and $B d$ zoospore size and zoosporangium size.

\section{Results}

Assessing Virulence of $\mathrm{Bd}-B r a z i l$ and $\mathrm{Bd}-\mathrm{GPL}$ isolates to Wood Frogs Infected as Larvae

The ranked mortality (from highest to lowest) for frogs exposed to the four $B d$ isolates was: JEL258 (Bd-GPL), JEL404 (Bd-GPL), UM142 (Bd-Brazil), and JEL423 (Bd-GPL) (Fig. 1). JEL423 (Bd-GPL) was the only isolate that did not cause significant mortality of Lithobates sylvaticus compared to the control treatment (ANOVA: $F_{[4,15]}=24.812, P<$ 0.001). The post-hoc test showed that isolate JEL258 (Bd-GPL) caused significantly higher mortality than the other isolates. 
$\mathrm{Bd}$ isolates, Phenotypes, and Genetic Characterization

Eight $B d$ isolates from seven different localities in Brazil varied significantly in the diameter of zoospores $\left(\right.$ ANOVA: $\left.F_{[7,472]}=12.854, P<0.001\right)$ and zoosporangia $\left(F_{[7,472]}=\right.$ 56.943, $P<0.001) . B d$-Brazil zoospore diameter averaged less than most $B d$-GPL isolates, and was among the smallest of all measured isolates (Table S1, S2). Although isolates differed significantly, we found no geographical clustering of similar phenotypes. Finally, neither zoospore $(r=-0.392, P=0.388)$ nor zoosporangium size $(r$ $=-0.236, P=0.115)$ was significantly correlated with genotype (Fig. 2).

\section{Climatic Correlates of Phenotype}

We found no significant associations between environmental variables and $B d$ phenotypes [Zoospore size (latitude $-F_{[1,6]}=2.406, \beta=-0.183, P=0.172$; elevation $F_{[1,6]}=0.462, \beta=-0.001, P=0.346$; mean annual precipitation $-F_{[1,6]}=0.064, \beta=-$ $0.001, P=0.808$; mean annual temperature $-F_{[1,6]}=0.475, \beta=0.004, P=0.377$ ). Zoosporangium size (latitude $-F_{[1,6]}=0.497, \beta=-1.851, P=0.507$; elevation $-F_{[1,6]}=$ $0.039, \beta=0.001, P=0.850 ;$ mean annual precipitation $-F_{[1,6]}=0.297, \beta=-0.001, P=$ 0.605; mean annual temperature $\left.\left.-F_{[1,6]}=0.061, \beta=-0.020, P=0.813\right)\right]$.

\section{Discussion}

Host populations require sufficient genetic variation and time to evolve resistance to novel pathogens (Ewald 1995). Therefore, newly introduced pathogen lineages often pose larger threats to host populations than locally endemic ones (Daszak et al., 2000; 
Duffy et al., 2007; Farrer et al., 2011). We thus predicted that our North American host Lithobates sylvaticus would be more susceptible to $B d$-Brazil and the Panamanian isolate $B d$-GPL JEL423 than to local $B d$-GPL isolates, which have not caused known recent amphibian declines and may have been present in the northeastern U.S.A. for over a century (Schloegel et al., 2012; Talley et al., 2015; Jenkinson et al., 2016). Contrary to our predictions, however, our focal host experienced high mortality rates when infected with two local $B d$-GPL isolates but did not experience significant mortality when infected with the Panamanian GPL isolate, despite experimental studies showing high virulence of Panamanian GPL while infecting other North American amphibians (Gahl et al., 2011, Gahl et al., 2012). Moreover, the virulence of our Bd-Brazil isolate fell at the high end of the distribution of virulence exhibited by GPL.

We found that $B d$-GPL isolates from Brazil show significant phenotypic variation. Other studies have also documented high variation in zoospore and zoosporangium size of $B d$ from different regions, and sometimes at very small spatial scales (Fisher et al., 2009; Farrer et al., 2011; Schloegel et al., 2012; Flechas et al., 2013; Lambertini et al., 2016). These findings suggest that $B d$ can evolve in response to selective pressures imposed by their hosts and/or the environment (LoVerde et al., 1985; Altizer et al., 2003; Thrall \& Burdon 2003). Although Bd zoospore and zoosporangium sizes from different sampling localities differed significantly, these two phenotypic metrics were not spatially clustered or linked to any environmental predictor that we tested. This result indicates that environmental variation might not play a major role in shaping $B d$ phenotypic differentiation. Because $B d$ is a host-generalist pathogen among amphibians, host density, species diversity, and relative abundance could modulate 
host-selective pressures independent of the environment. This potential effect of host community structure in shaping $B d$ phenotypes might help explain the observed variation in susceptibility among different amphibian guilds (Lips et al., 2003; Becker et al., 2014) and the reported differences in virulence among genetically similar $B d$ isolates (Gahl et al., 2012).

Previous studies indicate that smaller zoosporangium size is linked to decreased virulence, and the mechanism could be that larger zoosporangia cause greater skin damage (Fisher et al., 2009; Farrer et al., 2011; Lambertini et al., 2016). For instance, an isolate from endemic $B d$-Cape produced both lower host infection intensities and smaller average zoosporangium size when compared to Bd-GPL (Farrer et al., 2011). Furthermore, $B d$-Brazil caused lower mortality of our experimental hosts than JEL258 in addition to having smaller zoospore size (3.8 vs. $5.4 \mu \mathrm{m}$; Schloegel et al., 2012). Larger zoosporangia are expected to produce more and larger zoospores (Mitchell et al., 2008), and this variation in $B d$ phenotypes could potentially influence both transmission dynamics and virulence (Woodhams et al., 2008). Unfortunately, we lack phenotypic information for JEL404 and JEL423 to test for this relationship across all Bd isolates and we have not tested virulence of any of the isolates used to generate our measurements, which precludes making any further inferences about zoospore size and virulence.

A second potential mechanism to explain the observed link between phenotype and virulence among $B d$ isolates is genotypic differentiation (Farrer et al., 2013). However, we found an unexpected lack of correlation between genotypic divergence and zoospore and zoosporangium sizes in our sample. Our results differ from a similar study of mostly European $B d$ isolates, where genetic distance predicted average 
zoosporangium size but not zoospore production (Fisher et al., 2009). This pattern could arise from localized adaptation to varying environments, but this hypothesis is not supported by our environmental analyses. Variation could also be due to epigenetic differences among isolates or microevolution due to mitotic recombination or changes in chromosome copy number as has been observed to occur rapidly in culture (Refsnider et al., 2015). Nonetheless, the most likely explanation for the observed discordant genotypic and phenotypic variation among isolates is local adaptive divergence of $B d$ to host species, populations, or communities. Although our data cannot specifically test these mechanisms, they suggest that $B d$ virulence and phenotype will only partially be explained by genotypic differences.

In our study the narrowly distributed $B d$-Brazil had virulence comparable to an average $B d-G P L$ isolate. These findings, along with the large phenotypic and genotypic variation in $B d-G P L$ at very narrow geographic ranges independent of environmental conditions, underscore the potential for rapid diversification and flexibility of $B d$-GPL as a globally invasive lineage (Farrer et al., 2013). Our results also indicate that if $B d$-Brazil could spread from Brazil to the U.S.A., it could become a novel disease-causing agent in North America. Thus, further investigation on the epidemiology of $B d$-Brazil is needed. Our $B d$-Brazil isolate caused $\sim 50 \%$ mortality of our experimental NorthAmerican host, indicating that lineages endemic in one region might cause negative effects if introduced to naïve populations. Future work should culture additional $B d$ Brazil isolates to test how variable virulence is within this clade and also to test whether $B d$-Brazil is less virulent than $B d$-GPL in Brazilian host species. In addition, the large observed variation in zoospore and zoosporangium sizes may be linked to virulence, 
and future experiments might inform the role that differences in ploidy levels have in infection dynamics, even when isolates are genetically closely related. Characterizing phenotypes, genotypic diversity, and above all, virulence of $B d$ lineages and isolates has important implications for understanding the consequences of $B d$ diversity globally.

\section{Acknowledgments}

Our collaborative work was funded by grants and fellowships from the São Paulo Research Foundation (FAPESP \#2011/51694-7), National Council for Scientific and Technological Development (CNPq \#405285/2013-2; \#302589/2013-9; \#300980/20140; \#312895/2014-3), and a Catalyzing New International Collaborations Grant from the National Science Foundation (NSF \#OISE-1159513). 


\section{References}

Altizer, S., Harvell, D., Friedle, E., 2003. Rapid evolutionary dynamics and disease threats to biodiversity. Trends Ecol. Evol. 18, 589-596.

Altizer, S., Dobson, A., Hosseini, P., Hudson, P., Pascual, M., Rohani, P., 2006. Seasonality and the dynamics of infectious diseases. Ecol. Lett. 9, 467-484.

Bataille, A., Fong, J.J., Cha, M., Wogan, G.O.U., Baek, H.J., Lee, H., Min, M.S., Waldman, B., 2013. Genetic evidence for a high diversity and wide distribution of endemic strains of the pathogenic chytrid fungus Batrachochytrium dendrobatidis in wild Asian amphibians. Mol. Ecol. 22, 4196-4209.

Becker, C.G., Zamudio, K.R., 2011. Tropical amphibian populations experience higher disease risk in natural habitats. Proc. Natl. Acad. Sci. 108, 9893-9898.

Becker, C.G., Rodriguez, D., Toledo, L.F., Longo, A.V., Lambertini, C., Correa, D.T., Leite, D.S., Haddad, C.F.B., Zamudio, K.R., 2014. Partitioning the net effect of host diversity on an emerging amphibian pathogen. Proc. Roy. Soc. B. 281, 20141796.

Becker, C.G., Rodriguez, D., Longo, A.V., Toledo, L.F., Lambertini, C., Leite, D.S., Haddad, C.F.B., Zamudio, K.R., 2016a. Deforestation, host community structure, and amphibian disease risk. Basic Appl. Ecol. 17, 72-80.

Becker, C.G., Rodriguez, D., Lambertini, C., Toledo, L.F., Haddad, C.F.B., $2016 b$. Historical dynamics of Batrachochytrium dendrobatidis in Amazonia. Ecography DOI:10.5061/dryad.h3112.

Berger, L., Speare, R., Daszak, P., Green, D.E., Cunningham, A.A., Goggin, C.L., Slocombe, R., Ragan, M.A., Hyatt, A.D., McDonald, K.R., Hines, H.B., Lips, K.R., 
Marantelli, G., Parkes, H., 1998. Chytridiomycosis causes amphibian mortality associated with population declines in the rain forests of Australia and Central America. Proc. Natl. Acad. Sci. 95, 9031-9036.

Cheng, T.L., Rovito, S.M., Wake, D.B., Vredenburg, V.T., 2011. Coincident mass extirpation of neotropical amphibians with the emergence of the infectious fungal pathogen Batrachochytrium dendrobatidis. Proc. Natl. Acad. Sci. 108, 95029507.

Colhoun, J., 1973. Effects of environmental factors on plant disease. Annu. Rev. Phytopathol. 11, 343-364.

Daszak, P., Cunningham, A.A., Hyatt, A.D., 2000. Emerging infectious diseases of wildlife - threats to biodiversity and human health. Science $287,443-449$.

Duffy, M.A., Sivars-Becker, L., 2007. Rapid evolution and ecological host-parasite dynamics. Ecol. Lett. 10, 44-53.

Epstein, P.R., 2001. Climate change and emerging infectious diseases. Microbes Infect. $3,747-754$.

Eterovick, P.C., Carnaval, A.C.O.D., Borges-Nojosa, D.M., Silvano, D.L., Segalla, M.V., Sazima, I., 2005. Amphibian declines in Brazil: An Overview. Biotropica 37, 166179.

Ewald, P.W. 1995. The evolution of virulence - a unifying link between parasitology and ecology. J Parasitol. 81, 659-669.

Farrer, R.A., Weinert, L.A., Bielby, J., Garner, T.W.J., Balloux, F., Clare, F., Bosch, J., Cunningham, A.A., Weldon, C., du Preez, L.H., Anderson, L., Pond, S.L.K., Shahar-Golan, R., Henk, D.A., Fisher, M.C., 2011. Multiple emergences of 
genetically diverse amphibian-infecting chytrids include a globalized hypervirulent recombinant lineage. Proc. Natl. Acad. Sci. 108, 18732-18736.

Farrer, R.A., Henk, D.A., Garner, T.W.J., Balloux, F., Woodhams, D.C., Fisher, M.C., 2013. Chromosomal copy number variation, selection and uneven rates of recombination reveal cryptic genome diversity linked to pathogenicity. PLoS Genet. 9, e1003703.

Fisher, M.C., Bosch, J., Yin, Z., Stead, D.A., Walker, J., Selway, L., Brown, A.J.P., Walker, L.A., Gow, N.A.R., Stajich, J.E., Garner, T.W.J., 2009. Proteomic and phenotypic profiling of the amphibian pathogen Batrachochytrium dendrobatidis shows that genotype is linked to virulence. Mol. Ecol. 18, 415-429.

Flechas, S.V., Medina, E.M., Crawford, A.J., Sarmiento, C., Cardenas, M.E., Amezquita, A., Restrepo, S., 2013. Characterization of the first Batrachochytrium dendrobatidis isolate from the Colombian Andes, an amphibian biodiversity hotspot. EcoHealth 10, 72-76.

Gahl, M.K. Pauli, B.D., Houlahan, J.E. 2011. Effects of chytrid fungus and a glyphosatebased herbicide on survival and growth of wood frogs (Lithobates sylvaticus) Ecol. Appl. 21, 2521-2529.

Gahl, M.K, Longcore, J.E., Houlahan, J.E. 2012. Varying responses of northeastern North American amphibians to the chytrid pathogen Batrachochytrium dendrobatidis. Conserv. Biol. 26, 135-141.

Haddad, C.F.B., Toledo, L.F., Prado, C.P.A., Loebman, D., Gasparini, J.L., Sazima, I., 2013. Guia dos Anfíbios da Mata Atlântica: Diversidade e Biologia. Anolis Books, São Paulo 
Harvell, C.D., Mitchell, C.E., Ward, J.R., Altizer, S., Dobson, A.P., Ostfeld, R.S., Samuel, M.D., 2002. Climate warming and disease risks for terrestrial and marine biota. Science 296, 2158-2162.

Heyer, W.R., Rand, A.S., Cruz, C.A.G., Peixoto, O.L., 1988. Decimations, extinctions, and colonizations of frog populations in southeastern Brazil and their evolutionary implications. Biotropica 20, 230-235.

Hijmans, R.J., 2005. Very high resolution interpolated climate surfaces for global land areas. Int. J. Climatol. 25, 1965-1978.

James, T.Y., Litvintseva, A.P., Vilgalys, R., Morgan, J.A.T., Taylor, J.W., Fisher, M.C., Berger, L., Weldon, C., du Preez, L., Longcore, J.E., 2009. Rapid global expansion of the fungal disease chytridiomycosis into declining and healthy amphibian populations. PLoS Pathog. 5, 1-12.

James, T.Y., Toledo, L.F., Rodder, D., Leite, D.D., Belasen, A.M., Betancourt-Roman, C.M., Jenkinson, T.S., Soto-Azat, C., Lambertini, C., Longo, A.V., Ruggeri, J., Collins, J.P., Burrowes, P.A., Lips, K.R., Zamudio, K.R., Longcore, J.E., 2015. Disentangling host, pathogen, and environmental determinants of a recently emerged wildlife disease: lessons from the first 15 years of amphibian chytridiomycosis research. Ecol. Evol. 5, 4079-4097.

Jenkinson T.S., Betancourt Román C.M., Lambertini C., Aguilar-Valencia A., Rodriguez D., Nunes-de-Almeida C.H.L., Ruggeri J., Belasen A.M., da Silva Leite D., Zamudio K.R., Longcore J.E., Toledo L.F. and T.Y. James., 2016. Amphibiankilling chytrid in Brazil comprises both locally endemic and globally expanding populations. Mol. Ecol. 25: 2978-2996. 
Knapp, R.A., Morgan, J.A.T., 2006. Tadpole mouthpart depigmentation as an accurate indicator of chytridiomycosis, an emerging disease of amphibians. Copeia 2, $188-197$.

Lambertini, C., Becker, C.G., Jenkinson, T.S., Rodriguez, D., da Silva Leite, D., James, T.Y., Zamudio, K.R., Toledo, L.F., 2016. Local phenotypic variation in amphibiankilling fungus predicts infection dynamics. Fungal Ecol., 20, 15-21.

Lips, K.R., Reeve, J.D., Witters, L.R. 2003. Ecological traits predicting amphibian population declines in Central America. Conserv. Biol. 17, 1078-1088.

Lips, KR., Diffendorfer, J., Mendelson, J.R., Sears, M.W., 2008. Riding the wave: reconciling the roles of disease and climate change in amphibian declines. PLoS Biol. 6, e72.

Lomolino, M.V., Riddle, B.R., Brown, J.H., 2009. The geographic range as a reflection of the niche. Biogeography (3rd ed.) Sunderland, Mass p73

Longcore, J.E., Pessier, A.P., Nichols, D.K., 1999. Batrachochytrium dendrobatidis gen. et sp. nov., a chytrid pathogenic to amphibians. Mycologia 91, 219-227.

LoVerde, P.T., Dewald, J., Minchella, D.J., Bosshardt, S.C., Damian, R.T., 1985. Evidence for host-induced selection in Schistosoma mansoni. J. Parasitol. 71, 297-301.

Mitchell, K.M., Churcher, T.S., Garner, T.W.J., Fisher, M.C., 2008. Persistence of the emerging pathogen Batrachochytrium dendrobatidis outside the amphibian host greatly increases the probability of host extinction. Proc. Roy. Soc. B. 275, 329334. 
Morehouse, E.A., James, T.Y., Ganley, A.R.D., Vilgalys, R., Berger, L., Murphy, P.J., Longcore, J.E., 2003. Multilocus sequence typing suggests the chytrid pathogen of amphibians is a recently emerged clone. Mol. Ecol. 12, 395-403.

Morgan, J.A.T., Vredenburg, V.T., Rachowicz, L.J., Knapp, R.A., Stice, M.J., Tunstall, T., Bingham, R.E., Parker, J.M., Longcore, J.E., Moritz, C., Briggs, C.J., Taylor, J.W., 2007. Population genetics of the frog-killing fungus Batrachochytrium dendrobatidis. Proc. Natl. Acad. Sci. 104, 13845-13850.

Pounds, J.A., Bustamante, M.R., Coloma, L.A., Consuegra, J.A., Fogden, M.P.L., Foster, P.N., La Marca, E., Masters, K.L., Merino-Viteri, A., Puschendorf, R., Ron, S.R., Sanchez-Azofeifa, G.A., Still, C.J., Young, B.E., 2006. Widespread amphibian extinctions from epidemic disease driven by global warming. Nature 439, $161-167$.

Reece, S.E., Ramiro, R.S., Nussey, D.H., 2009. Plastic parasites: sophisticated strategies for survival and reproduction? Evol. Appl. 2, 11-23.

Refsnider, J.M., Poorten, T.J., Langhammer, P.F., Burrowes, P.A., Rosenblum, E.B., 2015. Genomic correlates of virulence attenuation in the deadly amphibian chytrid fungus, Batrachochytrium dendrobatidis. G3 (Bethesda) 1, 2291-2298.

Rodriguez, D., Becker, C.G., Pupin, N.C., Haddad, C.F.B., Zamudio, K.R., 2014. Longterm endemism of two highly divergent lineages of the amphibian-killing fungus in the Atlantic Forest of Brazil. Mol. Ecol. 23, 774-787.

Rosenblum, E.B., James, T.Y., Zamudio, K.R., Poorten, T.J., Ilut, D., Rodriguez, D., Eastman, J.M., Richards-Hrdlicka, K., Joneson, S., Jenkinson, T.S., Longcore, J.E., Olea, G.P., Toledo, L.F., Arellano, M.L., Medina, E.M., Restrepo, S., 
Flechas, S.V., Berger, L., Briggs, C.J., Stajich, J.E., 2013. Complex history of the amphibian-killing chytrid fungus revealed with genome resequencing data. Proc. Natl. Acad. Sci. 110, 9385-9390.

Schloegel, L.M., Toledo, L.F., Longcore, J.E., Greenspan, S.E., Vieira, C.A., Lee, M., Zhao, S., Wangen, C., Ferreira, C.M., Hipolito, M., Davies, A.J., Cuomo, C.A., Daszak, P., James, T.Y., 2012. Novel, panzootic and hybrid genotypes of amphibian chytridiomycosis associated with the bullfrog trade. Mol. Ecol. 21, 116.

Searle, C.L., Ochs, J.H., Caceres, C.E., Chiang, S.L., Gerardo, N.M., Hall, S.R., Duffy, M.A., 2015. Plasticity, not genetic variation, drives infection success of a fungal parasite. Parasitology 142, 839-848.

Talley, B.L., Muletz, C.R., Vredenburg, V.T., Fleischer, R.C., Lips, K.R., 2015. A century of Batrachochytrium dendrobatidis in Illinois amphibians (1888-1989). Biol. Conserv. 182, 254-261.

Thrall, P.H., Burdon, J.J., 2003. Evolution of virulence in a plant host-pathogen metapopulation. Science 299, 1735-1737.

Toledo, L.F., Haddad, C.F.B., Carnaval, A.O.Q.C., Britto, F.B., 2006. A Brazilian anuran (Hylodes magalhaesi: Leptodactylidae) infected by Batrachochytrium dendrobatidis: a conservation concern. Amph. Rept. Conserv. 4, 17-21.

Toledo, L.F., Batista, R.F., 2012. Integrative study of Brazilian anurans: relationship between geographic distribution and size, environment, taxonomy, and conservation. Biotropica 44, 785-792. 
Voyles, J., Young, S., Berger, L., Campbell, C., Voyles, W.F., Dinudom, A., Cook, D., Webb, R., Alford, R.A., Skerratt, L.F., Speare, R., 2009. Pathogenesis of chytridiomycosis, a cause of catastrophic amphibian declines. Science 326, 582585.

Weygoldt, P. 1989. Changes in the composition of mountain stream frog communities in the Atlantic mountains of Brazil: Frogs as indicators of environmental deteriorations? Stud. Neotrop. Fauna Environ. 24, 249-255.

Woodhams, D.C., Alford, R.A., Briggs, C.J., Johnson, M., Rollins-Smith, L.A., 2008. Life-history trade-offs influence disease in changing climates: strategies of an amphibian pathogen. Ecology 89, 1627-1639.

Yap, K.P., Gan, H.M., The, C.S.J., Chai, L.C., Thong, K.L., 2014. Comparative genomics of closely related Salmonella enterica serovar Typhi strains reveals genome dynamics and the acquisition of novel pathogenic elements. BMC Genomics 15, 1007.

Zolan, M.E., Pukkila, P.J., 1986. Inheritance of DNA methylation in Coprinus cinereus. Mol. Cellular Biol. 6, 195-200. 


\section{Figure Legends}

Figure 1. Comparison of post-metamorph mortality in experimental infections with four $B d$ isolates: three GPL isolates (JEL404 and JEL 258 from Maine; JEL423 from Panama) and one $B d$-Brazil isolate (UM142). Bd-Brazil and two Bd-GPL isolates resulted in significantly higher mortality of $L$. sylvaticus metamorphs compared to the control treatment. Different letters indicate statistically different groups in Fisher LSD test.

Figure 2. Scaled genotypic distance (DGEN/GENmax) against scaled zoospore size (DZSP/DZSPmax; filled circles and solid line) and scaled zoosporangium size (DSPOR/DSPORmax; empty circles and dashed line). 
Figure 1.

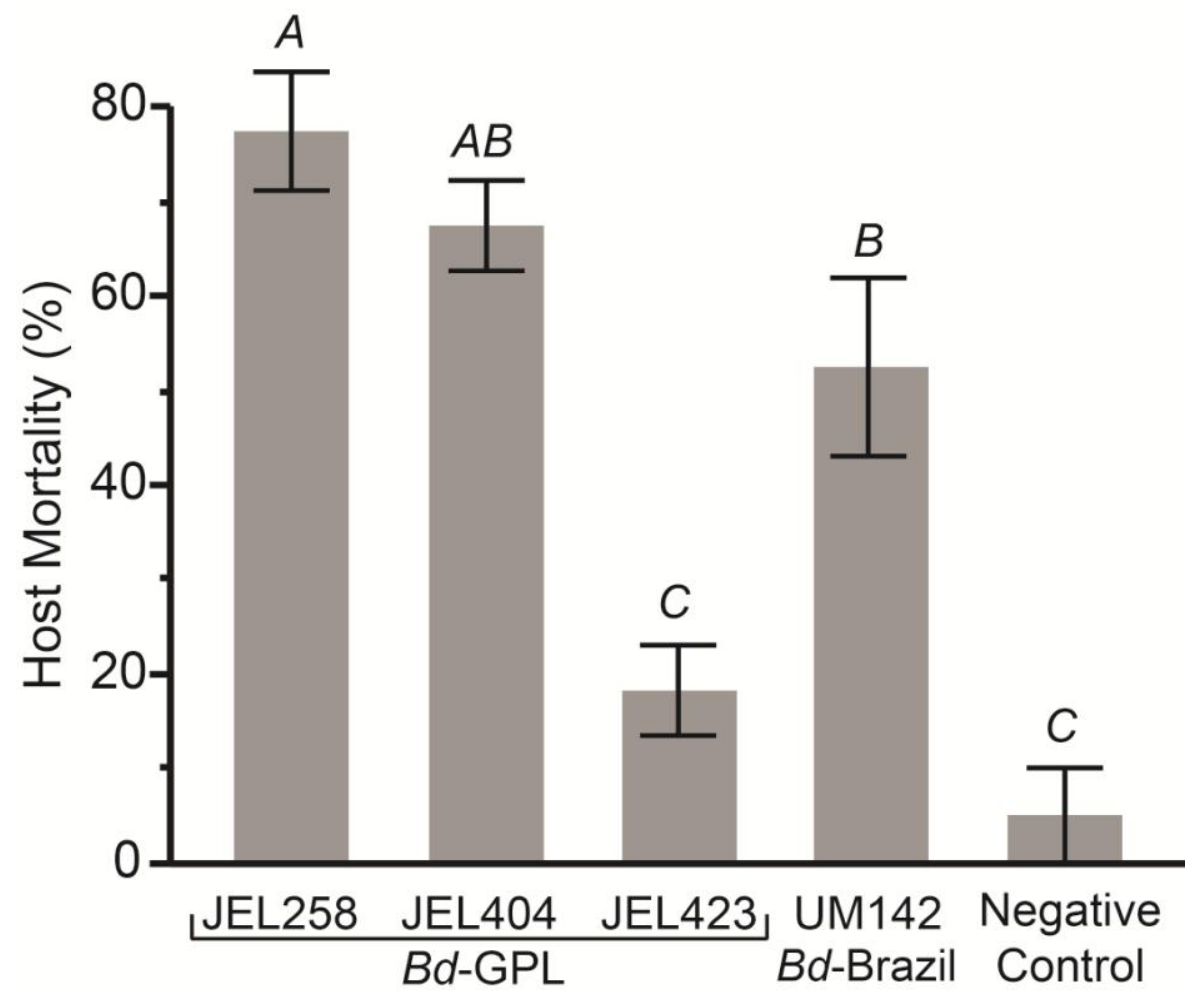


Figure 2.

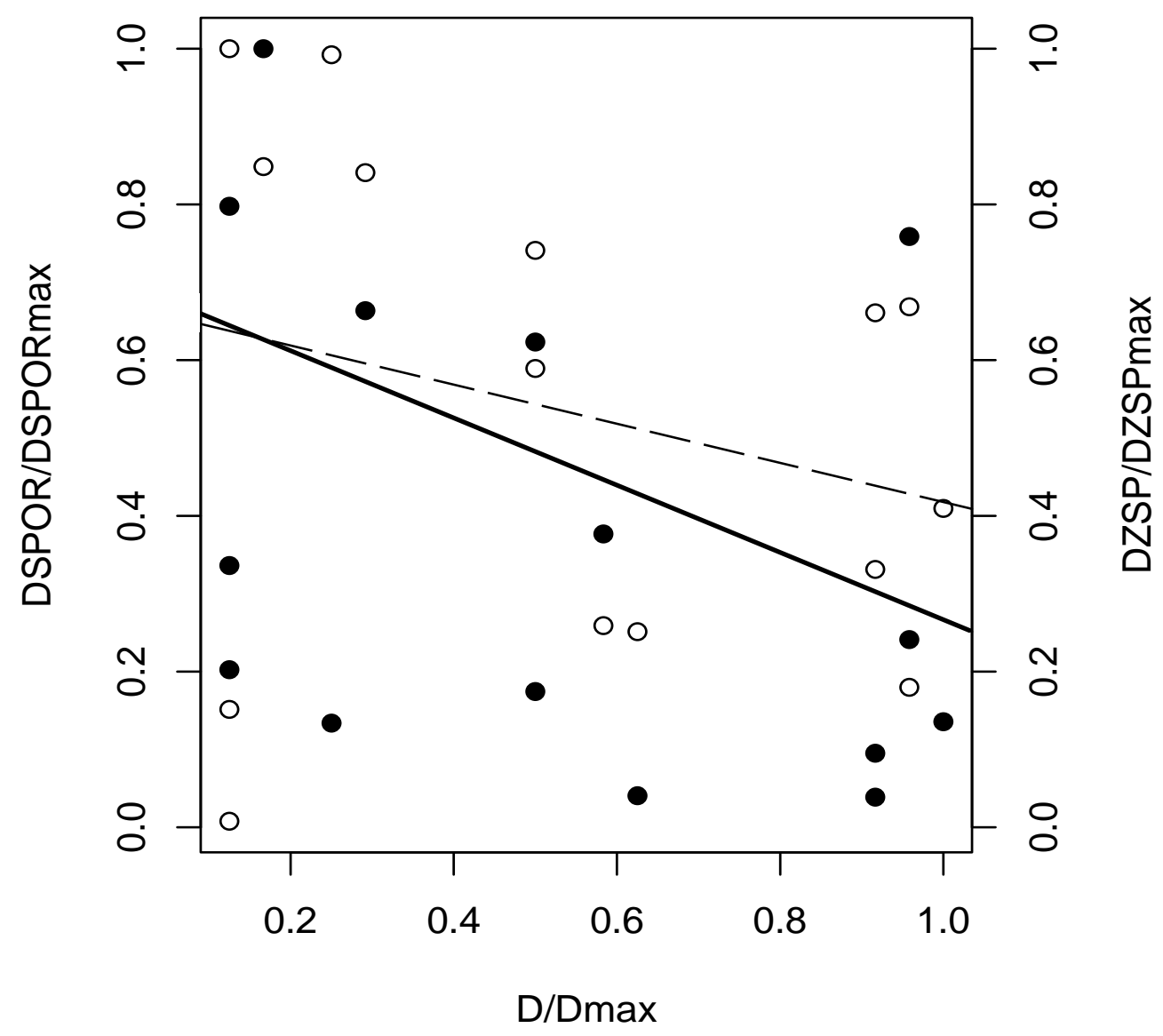


Table 1. Batrachochytrium dendrobatidis isolates (voucher code and lineage), zoospore and zoosporangium diameters $(\mu \mathrm{m})$ [mean \pm standard deviation (range)], host species, and collecting sites: latitude/longitude, elevation (above sea level), municipality, state (MG = Minas Gerais; SP = São Paulo; PR = Paraná).

\begin{tabular}{|c|c|c|c|c|c|c|c|}
\hline Isolate & Lineage & $\begin{array}{c}\text { Zoospore } \\
\text { diameter }(\mu \mathrm{m})\end{array}$ & $\begin{array}{c}\text { Zoosporangium } \\
\text { diameter }(\mu \mathrm{m})\end{array}$ & Amphibian host & $\begin{array}{l}\text { Latitude / } \\
\text { Longitude }\end{array}$ & $\begin{array}{c}\text { Elevation } \\
(\mathrm{m})\end{array}$ & Locality \\
\hline CLFT 001 & Bd-Brazil & $\begin{array}{c}3.81 \pm 0.61 \\
(2.70-4.99)\end{array}$ & $\begin{array}{c}29.29 \pm 7.88 \\
(18.26-48.43)\end{array}$ & Hylodes japi & $\begin{array}{c}-23.249292 / \\
-46.949915\end{array}$ & 1100 & Jundiaí, SP \\
\hline CLFT 021 & $B d-G P L$ & $\begin{array}{c}4.29 \pm 0.56 \\
(2.99-5.37)\end{array}$ & $\begin{array}{c}31.40 \pm 6.51 \\
(18.86-49.99)\end{array}$ & Unidentified & $\begin{array}{c}-23.314360 / \\
-47.098605\end{array}$ & 705 & Cabreúva, SP \\
\hline CLFT 023 & $B d-G P L$ & $\begin{array}{c}3.79 \pm 0.65 \\
(2.47-5.52)\end{array}$ & $\begin{array}{c}33.17 \pm 6.48 \\
(23.56-49.67)\end{array}$ & Hypsiboas sp. & $\begin{array}{c}-22.866361 / \\
-46.033068\end{array}$ & 1540 & Camanducaia, MG \\
\hline CLFT 024.1 & $B d-G P L$ & $\begin{array}{c}4.49 \pm 0.55 \\
(3.55-6.07)\end{array}$ & $\begin{array}{c}36.35 \pm 5.73 \\
(26.93-58.84)\end{array}$ & Hylodes cardosoi & $\begin{array}{c}-25.358990 / \\
-48.878570\end{array}$ & 250 & Morretes, PR \\
\hline CLFT 026 & $B d-G P L$ & $\begin{array}{c}3.90 \pm 0.76 \\
(2.41-6.20)\end{array}$ & $\begin{array}{c}24.49 \pm 3.96 \\
(17.24-40.90)\end{array}$ & Hypsiboas faber & $\begin{array}{c}-24.590532 / \\
-48.626003\end{array}$ & 95 & Iporanga, SP \\
\hline CLFT 029-00 & $B d-G P L$ & $\begin{array}{c}3.66 \pm 0.54 \\
(2.68-5.37)\end{array}$ & $\begin{array}{c}21.45 \pm 3.75 \\
(13.22-33.85)\end{array}$ & $\begin{array}{l}\text { Hypsiboas cf. } \\
\text { albopunctatus }\end{array}$ & $\begin{array}{l}-23.241410 / \\
-46.937760\end{array}$ & 1120 & Jundiaí, SP \\
\hline CLFT 029-01 & $B d-G P L$ & $\begin{array}{c}4.21 \pm 0.69 \\
(2.70-5.79)\end{array}$ & $\begin{array}{c}23.69 \pm 4.56 \\
(16.59-38.09)\end{array}$ & Scinax hiemalis & $\begin{array}{c}-23.241410 / \\
-46.937760\end{array}$ & 1120 & Jundiaí, SP \\
\hline CLFT 034 & $B d-G P L$ & $\begin{array}{c}3.87 \pm 0.63 \\
(2.90-5.24)\end{array}$ & $\begin{array}{c}21.54 \pm 6.06 \\
(10.80-35.76)\end{array}$ & Hylodes phyllodes & $\begin{array}{c}-23.707690 / \\
-46.035859\end{array}$ & 271 & Biritiba-Mirim, SP \\
\hline
\end{tabular}

